\title{
The Thermophilic Actinomycetes in Mouldy Hay: Micropolyspora faeni sp.nov.
}

\author{
By T. CROSS AND ANN M. MACIVER \\ Postgraduate School of Studies in Biological Sciences, \\ University of Bradford, Bradford 7 \\ AND J. LACEY \\ Rothamsted Experimental Station, Harpenden, Hertfordshire
}

(Accepted for publication I2 August 1967)

SUMMARY

Taxonomic studies on the thermophilic oligosporic actinomycete chiefly responsible for the respiratory disease Farmer's Lung support the view that the organism was incorrectly identified as Thermopolyspora polyspora Hens. The organism belongs to the genus Micropolyspora Lechevalier et al. and is described as a new species Micropolyspora faeni.

\section{INTRODUCTION}

Mouldy hay associated with farmer's lung disease contains large numbers of actinomycete spores (Gregory \& Lacey, 1962, 1963a). The commonest thermophilic and mesophilic species were described by Corbaz, Gregory \& Lacey (I963) and spores of two of the thermophilic species named Thermopolyspora polyspora Hens and Micromonospora vulgaris Waksmen et al. have been shown to be the main source of 'farmer's lung hay' antigens (Pepys et al. 1963; Pepys \& Jenkins, 1965).

Micromonospora vulgaris Waksman, Umbreit \& Cordon (1939) and Thermoactinomyces vulgaris Tsiklinsky (I899) are synonymous (Kuster \& Locci, I964) and the latter name is now generally preferred (Festenstein et al. 1965). Examination of the thermophilic hay strains named Thermopolyspora glauca Corbaz, Gregory \& Lacey (1963) show that spores are produced singly on short sporophores borne laterally on the aerial hyphae in a raceme or pallisade-like structure. True spore formation on the substrate mycelium was not observed. These strains must therefore be placed in the species Thermomonospora viridis (Schuurmans, Olson \& San Clements, 1956) Kuster \& Locci (1963).

Since the work of Corbaz, et al. (1963) several papers have been published commenting on the taxonomy and descriptions of oligosporic actinomycetes and questioning the validity of the binomial Thermopolyspora polyspora Hens (Kosmachev, I964; Kalakutskii, I964; Krassilnikov, I964; Becker, Lechevalier \& Lechevalier, I965; Lechevalier \& Lechevalier, 1965; Lechevalier, Lechevalier \& Becker, I966), and Lacey suggested that the organisms isolated from hay should be referred to the genus Micropolyspora Lechevalier, Solotorovsky \& McDurmont, 1961 (Festenstein et al. 1965).

Because of the importance of the organism named Thermopolyspora polyspora Hens 
in farmer's lung disease and the confusion over the taxonomy of oligosporic actinomycetes, we have made further taxonomic studies on strains isolated from hay and other habitats.

\section{METHODS}

Isolation

Several oligosporic thermophilic actinomycetes were isolated from mouldy hay samples kindly supplied by Dr R. E. Taylor of the National Agricultural Advisory Service, Leeds. Isolations were made by using an Andersen sampler (Andersen, 1958) loaded with plates of either yeast extract isolation agar or half-strength nutrient agar containing $0.5 \mathrm{mg}$. cycloheximide/ $\mathrm{ml}$. to suppress fungal growth. The sampler was connected by a short length of rubber tube to a sterile sample tin ( $12 \times 6 \times 4$ in.) containing a weighed hay sample. The hay in the tin was shaken (for about $3 \mathrm{~min}$.) to suspend actinomycete spores and the air spora sampled for brief periods ( $30 \mathrm{sec}$.) by connecting the Andersen sampler to a small vacuum pump after allowing the larger particles to settle.

From plates incubated at $55^{\circ}$, colonies similar to those identified as Thermopolyspora polyspora by Corbaz, Gregory \& Lacey (1963) were subcultured and purified on glucose nutrient agar. The organism was isolated frequently from the hay samples studied; 50 isolates were examined in detail. They fell into a well-defined group when using morphology and pigmentation as main criteria. Isolate CUB 58 was chosen for detailed study; its growth rate and pigmentation differed very little from other isolates when grown on a range of media.

Other strains, from hay and grain samples, were isolated with the aid of an Andersen sampler suspended horizontally in a small wind tunnel (Gregory \& Lacey 1963a,b).

Isolated strains and strains originating from other laboratories (Table I) were compared with each other and with published descriptions of Micropolyspora and Thermopolyspora species.

Table I. Strains included in the taxonomic study

\begin{tabular}{|c|}
\hline \\
\hline A94 \\
\hline A4I 5 \\
\hline A 444 \\
\hline A445 \\
\hline A 446 \\
\hline A 447 \\
\hline A 448 \\
\hline CUB 58 \\
\hline A 443 \\
\hline
\end{tabular}

Given name and source of isolate

Thermopolyspora polyspora. Corbaz, Gregory \& Lacey type strain $T$. polyspora isolated from sputum. B. Moore. Exeter Micropolyspora brevicatena I086w. H. A. Lechevalier Micropolyspora sp. LL660. H. A. Lechevalier

T. polyspora isolated from mushroom compost (Fergus, 1964)

$T$. polyspora isolated from lung biopsy material (Wenzel et al. 1964)

Micropolyspora sp. isolated from moist, overheated barley grain

Micropolyspora sp. isolated from hay

Norcardia madurae Sal. I. M. P. Lechevalier (Gordon, 1966)

\section{Media}

The two media used for isolations were the yeast extract and half strength nutrient agars used by Corbaz et al. (1963). The other media used for characterization were as follows.

Nutrient agar with glucose. Nutrient agar (Oxoid) with I \% (w/v) glucose.

Glucose yeast extract agar. Glucose 10 g. yeast extract (Difco) 10 g.; $\mathrm{K}_{2} \mathrm{HPO}_{4}, 0.5 \mathrm{~g}$; agar $20 \mathrm{~g}$.; distilled water I 1.; $\mathrm{pH} \mathrm{6 \cdot 8-7 \cdot 0.}$ 
Casamino acid agar. Glucose, $3 \cdot 0$ g.; $\mathrm{NaNO}_{3}, 2 \cdot 0$ g.; $\mathrm{K}_{2} \mathrm{HPO}_{4}, \mathrm{I} \cdot 0 \mathrm{~g}$.; $\mathrm{MgSO}_{4} \cdot 7 \mathrm{H}_{2} \mathrm{O}$, $0.5 \mathrm{~g}$.; $\mathrm{KCl}, 0.5 \mathrm{~g}$.; $\mathrm{FeSO}_{4} .7 \mathrm{H}_{2} \mathrm{O}$, 0.01 g.; Casamino acids (Difco), 1.0 g.; agar, 15 g.; distilled water I 1.

Milk agar. Skim milk powder (Oxoid), Io g.; agar, I5 g. distilled water, $200 \mathrm{ml}$. This agar after autoclaving was poured as a thin layer on the surface of solid $2.0 \%$ water agar.

Defined medium. (Lechevalier, Solotorovsky \& McDurmont, I96I).

$V-8$ agar (SAB Manual, 1957).

Oatmeal agar. ISP (Shirling \& Gottlieb, 1966).

Inorganic salts starch agar. ISP (Shirling \& Gottlieb, 1966).

Peptone yeast extract iron agar. ISP (Shirling \& Gottlieb, 1966).

Glycerol asparagine agar. ISP (Shirling \& Gottlieb, 1966).

Cellulose agar. I \% (w/v) ball-milled Whatman powdered cellulose in carbon utilization medium ISP (Shirling \& Gottlieb, 1966).

Potato carrot agar. (Cross, Lechevalier \& Lechevalier, 1963).

Corn meal salts agar (Cross et al. 1963).

Potato glucose agar (Baldacci, Comasch, Scotti \& Spalla, I953).

Chitin agar (Lingappa \& Lockwood, 1962).

Nutrient agar (Oxoid).

Lab Lemco agar (Oxoid).

\section{Colonial morphology}

Cultures were examined directly on the surface of agar plates by using a $\times 40$ longworking-distance objective or phase microscopy. Slide cultures, prepared by the method of Colmer \& McCoy (1950), were dried and stained with Hucker's modified Gram stain. We classified the mycelium into: (I) substrate (primary) mycelium which grows into and forms a compact layer on the surface of the agar medium; (2) aerial (secondary) mycelium which arises from the substrate mycelium and grows into the air away from the agar surface.

Colour determinations, where given, refer to the following codes: $\mathbf{P}=$ Prauser selection Baumann Farbtonkarte (Prauser, I964) CHM = Color Harmony Manual tabs ISCC-NBS I 955 (Tresner \& Backus, 1963).

\section{Ability to grow at various temperatures}

Plates to be incubated at high temperatures were placed in incubators containing a tray of water to prevent excessive drying of the agar. For determining the growth temperature range a polythermostat similar in design to that described by Oppenheimer \& Drost-Hansen (1960) was used.

\section{RESULTS}

The thermophilic Micropolyspora sp. (A 445, A448, CUB 58) and strains named Thermopolyspora polyspora (A 94, A4I5, A 446, A 447) were very similar in morphology and pigmentation, and grew well on most of the media at $55^{\circ}$ and $49^{\circ}$. Colonies are raised and pale orange-yellow to yellow-brown in colour. The substrate mycelium in the agar and forming the colony bears short, straight chains of spores. The white aerial mycelium is short, and bears straight, short chains of spores both laterally and terminally. The strains can be classified within the genus Micropolyspora (Lechevalier 
et al. 196I), are readily differentiated from Micropolyspora brevicatena (Table 2), and constitute a new species within the genus.

\section{Description of Micropolyspora faeni Cross, Maciver \& Lacey sp.nov. (faeni-of hay) NCIB 9984}

Substrate mycelium. About $0.5-0.8 \mu$ in diameter. Hyphae branching, penetrating the agar medium and forming compact colonies which are at first colourless, becoming orange-yellow to yellow-brown. Short chains of spores can be seen on the substrate mycelium forming the colony and also beneath the surface of the agar (Pl. I, figs. 3-5). Occasionally intercalary spore or chlamydospore formation was observed in slide cultures ( $\mathrm{Pl} .2$, figs. 7,8 ).

\section{Table 2. Differential characteristics of Micropolyspora brevicatena and M. faeni}

Character

Growth at $50^{\circ}$ and $55^{\circ}$

Substrate mycelium

Spore chains
M. brevicatena I086w

Pale pink orange to pink
yellow brown (P.Oc2a-Oc4a)
Flexibilis (flexuous, wavy
to slightly coiled)

M. faeni A94

$+$

Orange yellow to yellow brown (P.Coo2a-Coo4a)

Rectus (straight, stiff)

Aerial mycelium. About $\mathrm{I} \cdot \circ \mu$ in diameter, white and abundant on certain media. Short chains of spores are borne on the aerial hyphae both laterally and terminally. The lateral chains are short (about 5 spores) while those at the tip may be longer (about 5-IO spores) (Pl. I, figs. I, 2). Spore chains on the substrate and aerial hyphae are very similar morphologically and show a beaded appearance in stained preparations, with conspicuous non-staining areas between each spore (Pl. 2, figs. 9, I0). Spores are globose to oval, sometimes irregular, smooth, $0 \cdot 7-\mathrm{I} \cdot 3 \mu$ long, in electron micrographs (Pl. 2, figs II, I2).

\section{Appearance on various media}

Descriptions refer to strain A 94 after growth at $55^{\circ}$. Some differences between strains were noted and detailed below.

Yeast extract agar. Growth good, substrate mycelium light orange brown (P.Coo2aCoo4a). Aerial mycelium with spores, developing slowly at the edge of the colony but growing upright and away from the centre of the colony. No soluble pigment.

$V-8$ agar. Growth good, substrate mycelium light orange-brown (P.CoozaCoo4a). Aerial mycelium production good, pale orange-yellow to pearl pink shell (CHM 3ca) initially becoming white on further incubation. Chains of spores (4-5 spores) on substrate mycelium after 2 days. Aerial mycelium short and coarse bearing short chains of spores (2-5 spores). Some brown soluble pigment.

Nutrient agar. Growth only moderate after 2 days but good after 5 days. Substrate mycelium pale buff (PCo4a) to cream (PCo6a) bearing single spores and chains of spores. Aerial mycelium developing after 3 days, off white to oyster white (CHM b) bearing chains of 5-7 spores. No soluble pigment. The strains exhibited similar characteristics on half strength nutrient agar. On nutrient agar + glucose growth was more rapid and abundant aerial mycelium evident after 2 days incubation. 
Oatmeal agar. Growth poor, restricted, colourless substrate mycelium bearing spore chains ( $3-5$ spores).

Lab Lemco agar. Good growth after 2 days incubation. Substrate mycelium cream buff (P.Coo5a) becoming pale orange brown (PCooza) after 5 days. Chains of spores on substrate mycelium. No aerial mycelium.

Glycerol asparagine agar. Growth good where inoculum is heavy but elsewhere only isolated colonies grow slowly. Substrate mycelium cream buff (P. Coo5a) becoming lighter on further incubation (P.Co6a) bearing single chains and short chains. Aerial mycelium absent.

Glucose yeast agar. Growth abundant after 2 days incubation. Substrate mycelium pale orange brown (P.Coo3m) bearing chains of spores. No aerial mycelium. No soluble pigment.

Casamino acid agar. Growth slow at first but appreciable colonies formed after 5 days incubation, light orange brown in colour (P.Coo2a). Short chains of spores on substrate mycelium. No aerial mycelium, except in strains A4I5, A448, CUB 58 where it was sparse, white. No soluble pigment.

Potato glucose agar. Growth limited after 2 days beoming moderate after 5 days incubation. Substrate mycelium pale brown (P.Coo4a) becoming paler on further incubation (P.Co6a) and bearing chains of spores. Aerial mycelium developing in patches, off white and bearing chains of spores (2-5-8 spores). No soluble pigment.

Inorganic salts-starch agar. Very thin colourless growth. No aerial mycelium. No starch hydrolysis detectable.

Peptone yeast extract iron agar. Growth good, pale orange brown with no aerial mycelium. No melanin pigment.

Potato carrot agar. Growth poor, pale brown colonies. No aerial mycelium.

Corn meal salts agar. Growth thin, pale brown colonies bearing chains of spores. No aerial mycelium.

Milk agar. Excellent growth, orange yellow colonies lacking aerial mycelium. No casein digestion.

Defined medium. Growth moderate after 3 days. Strains A 445, A 446, A 448 orange yellow; A 94, A4I5 and CUB 58 colourless to pale yellow. No aerial mycelium, no soluble pigment.

Chitin agar. Strains A94 and A4I5 no growth. Very thin transparent growth exhibited by strains A445, A446, A447, A 448 and CUB58. No clearing of colloidal chitin.

Cellulose agar. No growth.

\section{Effect of $p H$ value on growth}

Good growth was obtained on plates of nutrient agar buffered with phosphate over the range $\mathrm{pH} 6.0,6.3,7.4$ and 8.1 at $55^{\circ}$ and $49^{\circ}$. At $37^{\circ}$ good growth was obtained at $\mathrm{pH} 6.0$, moderate growth at $\mathrm{pH} 6.3$ and $7 \cdot 0$, and no growth at $\mathrm{pH} 8 \cdot \mathrm{I}$. Similar results were obtained for A 4I5. The other strains were less sensitive to $\mathrm{pH} 8 \cdot \mathrm{I}$ at $37^{\circ}$ but growth was always less than at $\mathrm{pH} 6 \cdot 0$.

\section{Effect of temperature on growth}

Micropolyspora faeni is a facultative thermophile or eurithermal thermophile (Gaughran, 1947) exhibiting growth on plates at $55^{\circ}$ and on some media at $37^{\circ}$. When incubated on agar slopes placed in a polythermostat, a wide range of growth tempera- 
tures were observed (Table 3), the range and extent of growth depending on the nature of the medium. The maximum growth temperatures observed in the polythermostat tubes were lower than those in agar-plate cultures and must reflect differences in aeration and humidity.

\section{Occurrence}

Micropolyspora faeni is a characteristic component of the microflora of very mouldy hays, which may cause farmer's lung disease in susceptible subjects. These are hays that have been baled when too wet and have subsequently heated spontaneously. Water contents in excess of $35 \%$ may permit heating to $50-70^{\circ}$ with the growth of abundant thermophilic and thermotolerant moulds and actinomycetes (Gregory, Lacey, Festenstein, Skinner, I963; Festenstein et al. 1965). Most $M$. faeni isolates were obtained from hay stored in a Dewar flask at $47 \%$ water content which heated to $6 \mathrm{I}^{\circ}$. Hay associated with cases of farmer's lung disease and respiratory disease in cattle yielded up to 133 colonies/g. dry wt hay under standard conditions in the wind tunnel (Gregory \& Lacey, 1963a). This is equivalent to about I \% of the blowable fraction of the spore load, or about $0.15 \%$ of the total (Gregory \& Lacey, $1963 b$ ).

Micropolyspora faeni has also been isolated from lung biopsy material (Wenzel, Emanuel, Lawton \& Magnin 1964), sputum (Moore, in Lacey \& Lacey, 1964), mushroom compost (Fergus, 1964) and from mouldy silage, barley grain, straw and sugar cane bagasse after self-heating, and the air of farm buildings where fodder was being stored or moved.

Table 3. Growth of Micropolyspora faeni A94 on slopes in a polythermostat after incubation for $67 \mathrm{hr}$

$\begin{array}{ccccc}\text { Temperature } & \begin{array}{c}\text { Half-strength } \\ \text { nutrient }\end{array} & \begin{array}{c}\text { Nutrient+ } \\ \text { glucose }\end{array} & \begin{array}{c}\text { Glucose+yeast } \\ \text { extract }\end{array} & \begin{array}{c}\text { Yeast } \\ \text { extract }\end{array} \\ 61 \cdot 4 & - & - & - & - \\ 59 \cdot 0 & - & (+) & - & - \\ 56 \cdot 7 & (+) & (+) & - & - \\ 54 \cdot 6 & + & ++ & (+) & - \\ 52 \cdot 3 & ++ & ++ & + & - \\ 50 \cdot 4 & ++ & ++ & ++ & (+) \\ 48 \cdot 1 & ++ & ++ & ++ & + \\ 46 \cdot 0 & ++ & ++ & ++ & + \\ 44 \cdot 0 & ++ & ++ & + & + \\ 42 \cdot 0 & ++ & ++ & + & + \\ 40 \cdot 0 & ++ & ++ & (+) & (+) \\ 38 \cdot 2 & ++ & ++ & (+) & (+) \\ 35 \cdot 8 & + & + & (+) & (+) \\ 34 \cdot 2 & (+) & (+) & (+) & (+) \\ 32 \cdot 5 & (+) & (+) & (+) & - \\ \text { Key: } & & & \end{array}$

\section{Pathogenicity}

Although Micropolyspora faeni has been isolated from sputum and lung biopsy material of farmer's lung patients, there is so far no evidence that it grows in the lung. However, M. faeni is a rich source of farmer's lung hay antigen, and corresponding precipitins are found in the sera of affected subjects. Inhalation of extracts of $M$. faeni, or of fractions of the antigen it produces, by affected subjects provokes symptoms of farmer's lung disease (Pepys et al., 1963; Pepys \& Jenkins, 1965). Farmer's lung is a 
disease of the peripheral parts of the broncho-pulmonary system. The spores of $M$. faeni, being about I $\mu$ diameter, are well suited for deposition in the alveolar region, where the reaction occurs. Since $M$. faeni has been identified as a cause of farmer's lung, this disease has been prescribed under the National Insurance (Industrial Injuries) Act 1946 , in Britain.

\section{DISCUSSION}

The genus Thermopolyspora was proposed by Henssen (1957) to include organisms forming unbranched aerial hyphae bearing short chains of conidia; her published descriptions and photographs do not have any reference to spores on the substrate mycelium. Her organism $T$. polyspora could therefore be considered as a thermophilic Streptomyces or Nocardia and it is unfortunate that it is now impossible to obtain any of her strains for comparative study. Henssen's descriptions were based on the type of sporulation produced only when the organism was grown in the presence of contaminating bacteria. Because of this, her taxon is considered to be illegitimate under the International Code of Nomenclature of Bacteria and Viruses (I958), Rule 24 g. (Becker, et al. 1965). However, under the International Code of Nomenclature of Bacteria (1966) Henssen's binomial would be valid since her description was based only on the actinomycete component of bacterially contaminated cultures. Also, no bacteria can be seen in her photographs of $T$. polyspora. Isolate A94 has been examined by $\mathrm{Dr}$ Henssen, who considers it to be distinct from T. polyspora (Henssen I957). Two further species have been included in the genus Thermopolyspora (Krassilnikov \& Agre, 1964) and both were reported to produce chains of spores on the aerial hyphae and from the mycelium on the surface of the colony. Thermopolyspora flexuosa was reported to produce short spiral spore-chains, and the individual spores to have a spiny membrane. The colonies were pale yellow brown to dark brown and the weakly developing aerial mycelium, white with a blue shade. Thermopolyspora rectivirgula had straight chains of smooth spores, colourless to slightly yellow colonies and abundant yellowish aerial mycelium. However, later that same year Krassilnikov (I964) noted that Thermopolyspora was a questionable genus. He stated that 'according to fruiting structures, the cultures of this genus do not differ from that of Micropolyspora. It is only more thermophilic, which in our opinion is not sufficient for their separation into a separate genus'. Thermopolyspora flexuosa K II 32 was examined by Becker et al. (1965) and found to produce a sporulation similar to that described by Henssen for T. polyspora. However, this type of sporulation is also characteristic of sporulating strains of Nocardia madurae (Gordon, I966) (see Pl. I, fig. 6) and the cell-wall composition of strain K-I I 32 was that of 'Type 3' actinomcyetes which includes $N$. madurae. There is thus some doubt as to whether these two species belong to the genus Micropolyspora.

A new species named Micropolyspora thermovirida was described by Kosmachev (1964). The organism is a facultative thermophil, bearing spore chains of $\mathrm{I}$ to 15 , occasionally 20 , spores and the aerial mycelium is greenish grey. A second new species named $M$. caesia was described by Kalakutskii (I964). Spores produced on the substrate and aerial hyphae are mostly single but occasionally in short chains of two, three or rarely four. The organism is mesophilic and produces a greyish blue aerial mycelium. These species broaden the definition of the genus Micropolyspora and their exact taxonomic position requires further investigation. They differ significantly from the properties described for $M$. faeni. 
Micropolyspora faeni A94 has a cell-wall composition of the Type IV or 'Nocardia type' actinomycetes, which include Micropolyspora brevicatena and other Micropolyspora strains (Becker, et al. 1965). Its morphology and method of spore formation is typical of the genus Micropolyspora and it differs from previously described species. It may be significant that $M$. brevicatena was also isolated from sputum. Details of the clinical history of the two patients concerned have not been published, except that they were being treated for tuberculosis. Symptoms of farmer's lung disease have sometimes been mistaken for tuberculosis, and this might suggest that $M$. brevicatena could cause a similar disease.

We thank Mr R. D. Woods for the electron micrographs. This investigation was supported by a grant from the Medical Research Council.

\section{REFERENCES}

ANDERSEN, A. A. (1958). New sampler for the collection, sizing and enumeration of viable airborne particles. J. Bact. 76, $47 \mathrm{I}$.

Baldacci, E., Comasch, G. F., ScotTi, T. \& Spalla, C. (1953). General criteria for the systematics of genera and species of Actinomyces and Micromonospora. VI Int. Congr. Microbiol. Roma. Symp. Actinomycetes (Suppl. Rend. Inst. Sup. San), p. 20.

Becker, B., Lechevalier, M. P. \& Lechevalier, H. A. (1965). Chemical composition of cell wall preparations from strains of various form genera of aerobic actinomycetes. Appl. Microbiol. r3, 236.

Colmer, A. A. \& McCoy, E. (1950). Some morphological and cultural studies on lake strains of Micromonospora. Trans. Wis. Acad. Sci. 40, 49.

Corbaz, R., Gregory, P. H. \& LACEY, M. E. (1963). Thermophilic and mesophilic actinomycetes in mouldy hay. J. gen. Microbiol. 32, 449.

Cross, T., Lechevalier, M. P. \& Lechevalier, H. (1963). A new genus of the Actinomycetales: Microellobosporia gen. nov. J. gen. Microbiol. 31, $42 \mathrm{I}$.

Fergus, C. L. (1964). Thermophilic and thermotolerant molds and actinomycetes of mushroom compost during peak heating. Mycologia 56, 267.

Festenstein, G. N., Lacey, J., Skinner, F. A., Kenkins, P. A. \& Pepys, J. (1965). Self heating of hay and grain in Dewar flasks and the development of farmers lung antigens. J. gen. Microbiol. 4I, 389.

Gaughran, L. R. L. (1947). The thermophilic microorganisms. Bact. Rev. II, 225.

GoRDON, R. E. (1966). Some criteria for the recognition of Nocardia madurea (Vincent) Blanchard. J. gen. Microbiol. 45, 355.

GREGORY, P. H. \& LACEY, M. E. (1962). Isolation of thermophilic actinomycetes. Nature, Lond. 195 , 95.

GREGORY, P. H. \& LACEY, M. E. (1963a). Mycological examination of dust from mouldy hay associated with Farmer's lung disease. J. gen. Microbiol. 30, 75.

Gregory, P. H. \& LACEY, M. E. (1963b). Liberation of spores from mouldy hay. Trans. Br. mycol. Soc. $46, \mathrm{I}$.

Gregory, P. H., Lacey, M. E., Festenstein, G. N. \& Skinner, F. A. (1963). Microbial and biochemical changes during the moulding of hay. J. gen. Microbiol. 33, 147.

HENSESN, A. (1957). Beiträge zur Morphologie und Systematik der thermophilen Actinomyceten. Arch. Mikrobiol. 26, 373.

KalAKUTSKi, L. V. (1964). A new species of the genus Micropolyspora-Micropolyspora caesia $\mathrm{n} . \mathrm{sp}$. Microbiology, Moscow 33, 765 .

Kosmachev, A. L. (1964). A new thermophilic actinomycete Micropolyspora thermovirida n.sp. Microbiology, Moscow 33, 235.

KrassiLINIKov, N. A. (1964). Systematic position of ray fungi among the lower organisms. Hindustan Antib. Bull. 7, 1. 
Journal of General Microbiology, Vol. 50, No. 3

Plate I

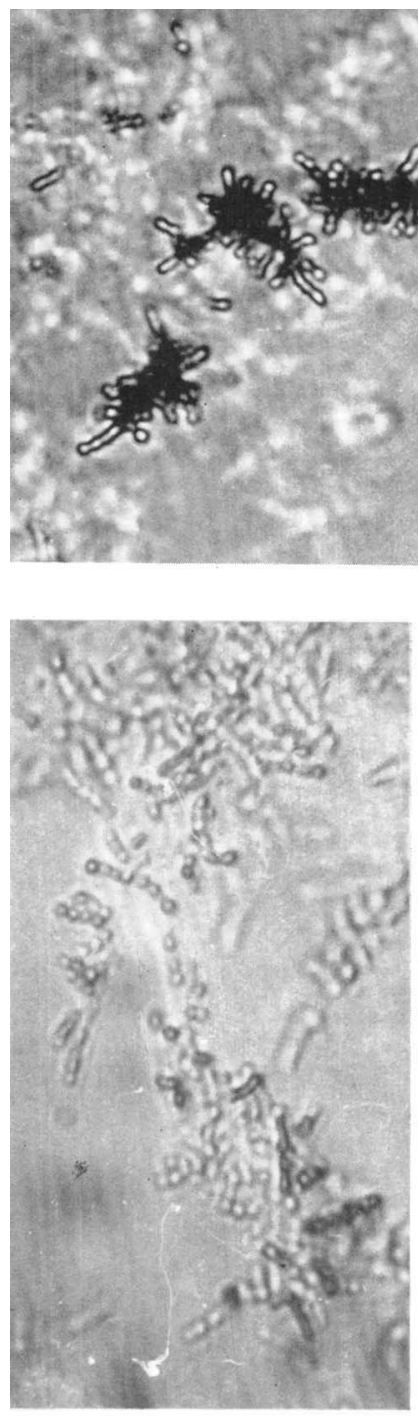

3

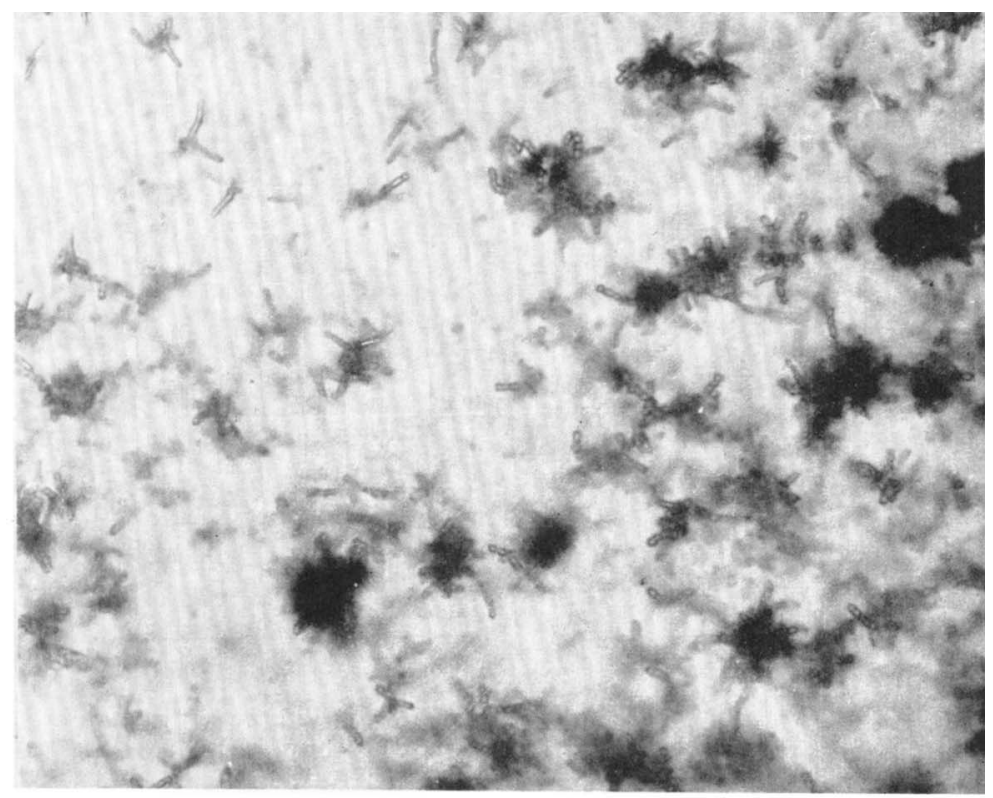

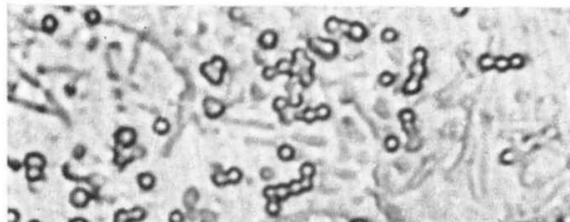

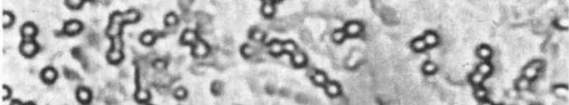
क० द. क के 3े० $80^{\circ} 0380.0 \%$

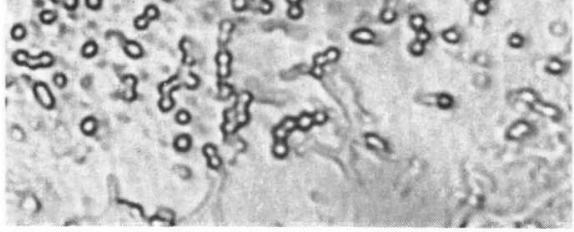

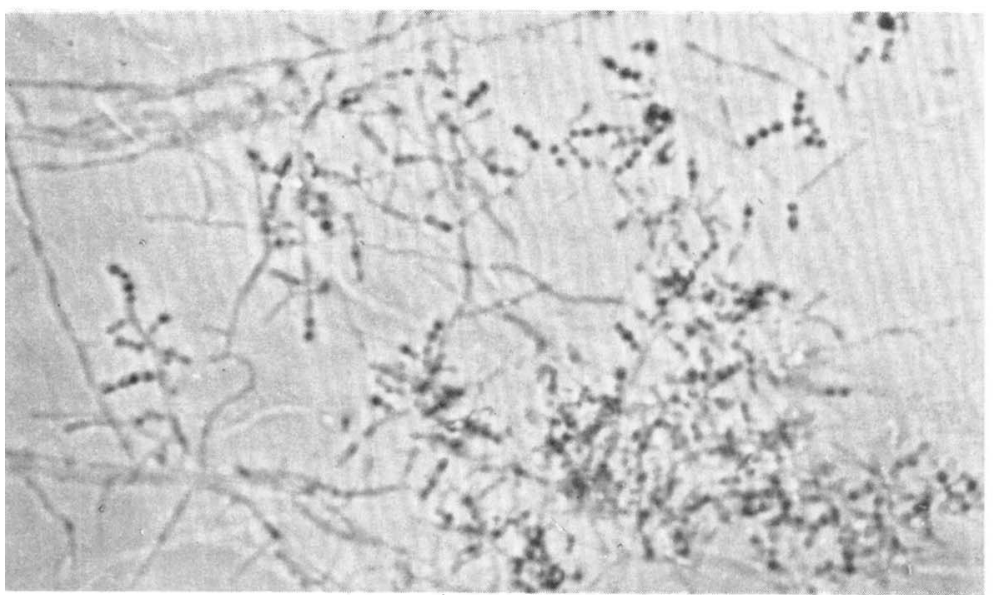


Journal of General Microbiology, Vol. 50, No. 3

Plate 2
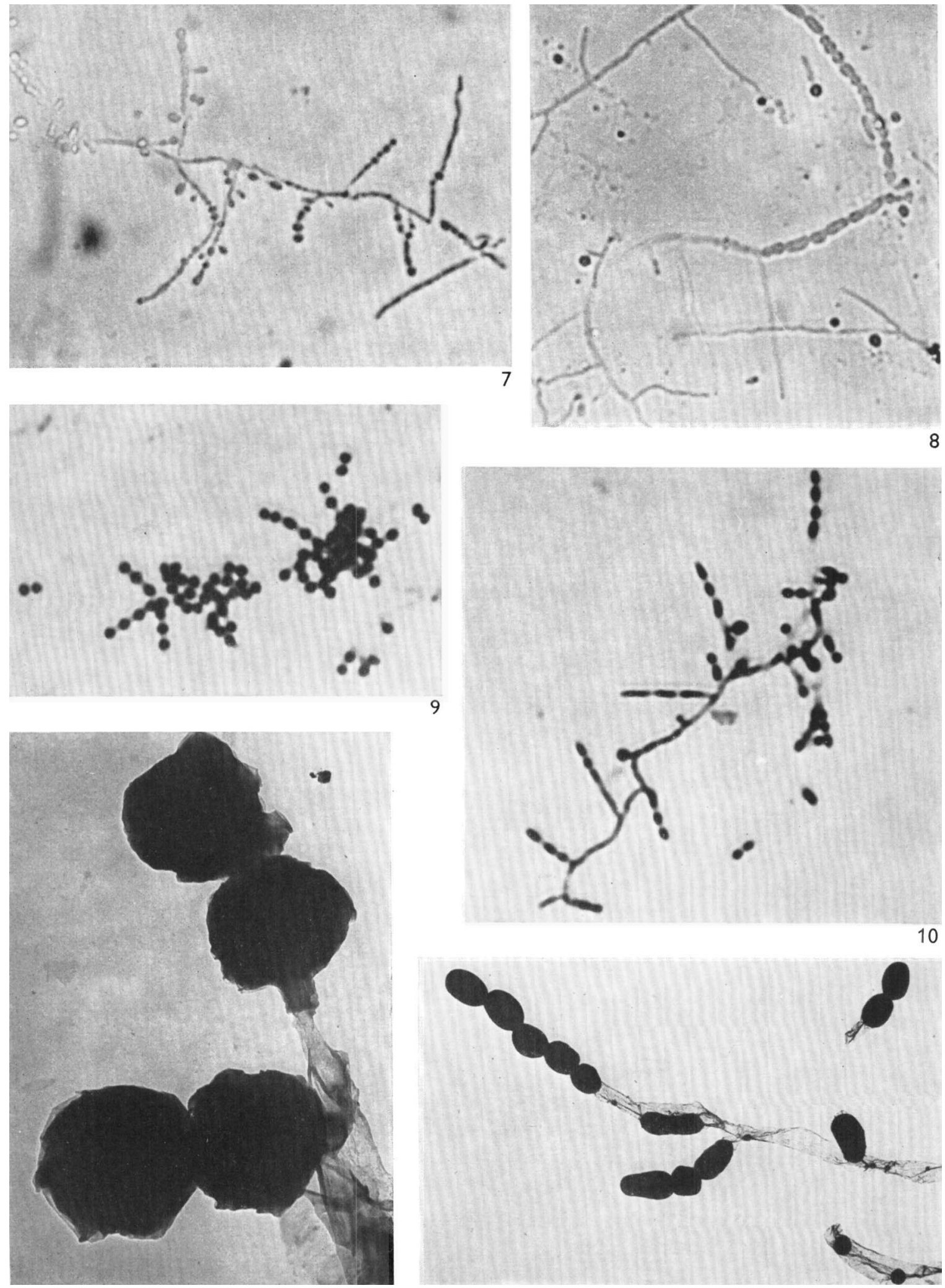

9
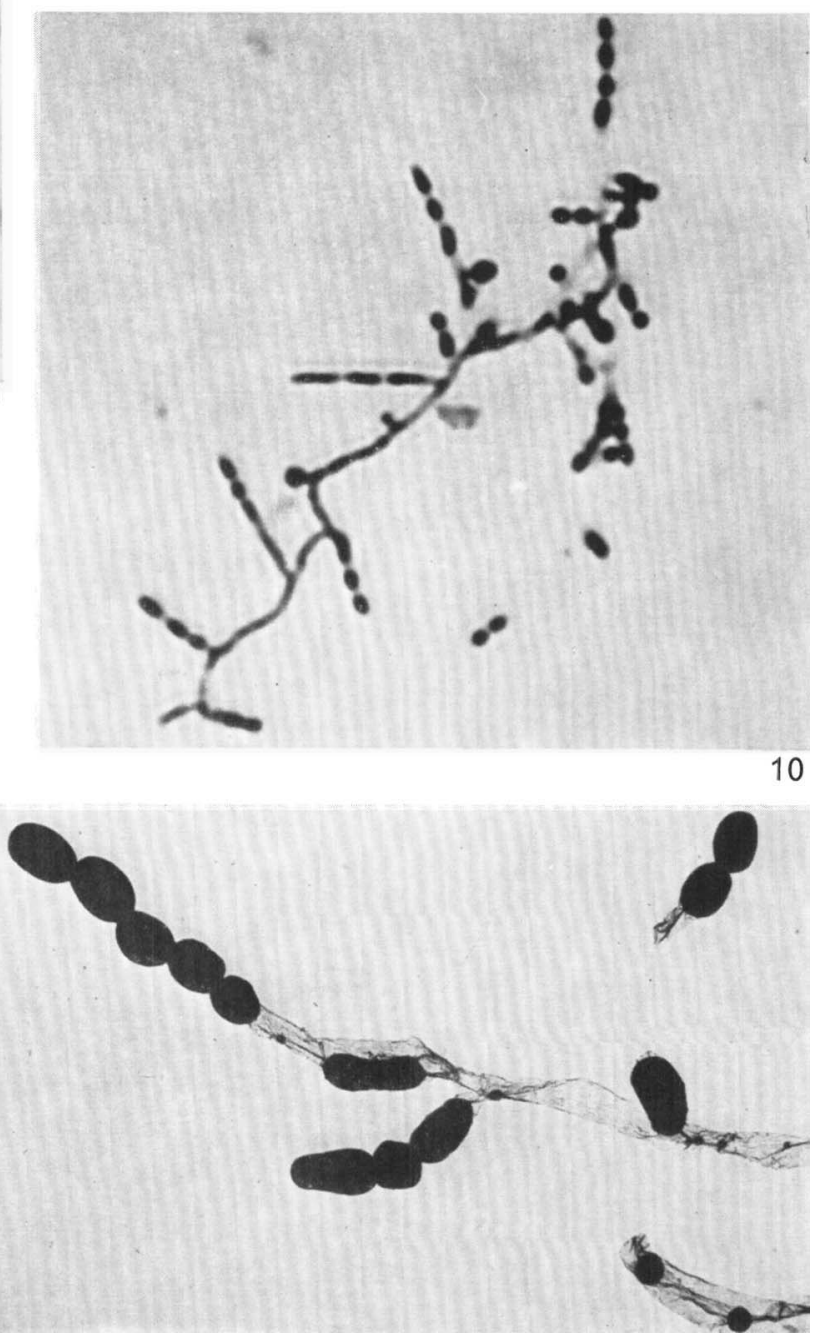
Krassilinikov, N. A. \& Agre, N.S. (1964). On two new species of Thermopolyspora. Hindustan Antib. Bull. 6, 97.

KUSTER, E. \& LOCCI, R. (1963). Transfer of Thermoactinomyces viridis. Schuurmans et al. 1956 to the genus Thermomonospora as Thermomonospora viridis (Schuurmans, Olson, San Clemente) Comb. nov. Int. Bull. bact. Nomencl. Taxon. 13, 313.

Kuster, E. \& Locci, R. (I964). Taxonomic studies on the genus Thermoactinomyces. Int. Bull. bact. Nomencl. Taxon. 14, 109.

LACEY, J. \& LACEY, M. E. (1964). Spore concentrations in the air of farm buildings. Trans. Br. mycol. Soc. $47,547$.

Lechevalier, H. A. \& Lechevalier, M. P. ( I965). Classification des actinomycètes aérobies basée sur leur morphologie et leur composition chemique. Ann. Inst. Pasteur, Paris 108, 662.

Lechevalier, H. A., Lechevalier, M. P. \& Becker, B. ( I966). Comparison of the chemical composition of cell walls of Nocardiae with that of other aerobic actinomycetes. Int. J. Syst. Bact. r6, I5I.

Lechevalier, H. A., Solotorovsky, M. \& McDurmont, C. I. (I96I). A new genus of the Actinomycetales: Micropolyspora gen. nov. J. gen. Microbiol. 26, i I.

LINGAPPA, Y. \& LOCKwoOd, J. L. (I962). Chitin media for selective isolation and culture of actinomycetes. Phytopathology 52, 317.

Oppenheimer, C. H. \& Drost-Hansen, W. (1960). A relationship between multiple temperature optima for biological systems and the properties of water. J. Bact. 8o, $2 \mathrm{I}$.

Pepys, J. \& Jenkins, P. A. (1965). Precipitin (F. L. H.) test in farmer's lung. Thorax $20,21$.

Pepys, J., Jenkins, P. A., Festenstein, G. N., Gregory, P. H., Lacey, M. E. \& Skinner, F. A. (I963). Farmer's Lung. Thermophilic actinomycetes as a source of 'farmer's lung hay' antigens. Lancet ii, 607.

Prauser, H. (1964). Aptness and application of colour codes for exact descriptions of colours of Streptomycetes. Z. allg. Mikrobiol. 4, 95.

SAB-Manual of Microbiological Methods (1957). Ed by M. J. Pelczar et al. New York: McGraw Hill.

Schuurmans, D. M., Olson, B. H. \& San Clemente, C. L. (1956). Production and isolation of Thermoviridin, an antibiotic produced by Thermoactinomyces viridis n.sp. Appl. Microbiol. 11, 6r.

Shirling, E. B. \& Gottlieb, D. ( I966). Methods for characterization of Streptomyces species. Int. J Syst. Bact. I6, 313 .

Tresner, H. D. \& Backus, E. J. (1963). System of color wheels for streptomycete taxonomy. Appl. Microbiol. II, 335.

Tsiklinsky, P. (1899). Sur les mucédinées thermophiles. Ann. Inst. Pasteur, Paris 13, 500.

Waksman, S. A., Umbreit, W. W. \& Cordon, T. C. (I939). Thermophilic actinomycetes and fungi in soils and composts. Soil Sci. 47, 37.

Wenzel, F. J., Emanuel, D. A., Lawton, B. R., \& Magnin G. E. (I964). Isolation of the causative agent of farmer's lung. Ann. Allerg. 22, 533.

\section{EXPLANATION OF PLATES}

\section{Plate I}

Fig. I. Aerial mycelium on potato dextrose agar Micropolyspora faeni cuB $58(\times 500)$.

Fig. 2. Aerial mycelium on yeast extract agar $M$. faeni CUB $58(\times 800)$.

Fig. 3. Substrate mycelium beneath surface of agar. Nutrient agar. $M$. faeni CUB $58(\times 850)$.

Fig. 4. Substrate mycelium beneath surface of agar. Yeast extract agar. Phase contrast $M$. faeni CUB58 $(\times 800)$.

Fig. 5. Spore chains on surface of colony growing in slide culture. v-8 agar. M. faeni A 94 ( $\times 980)$.

Fig. 6. Aerial mycelium of Nocardia madurae A443. Potato carrot agar $(\times 800)$.

\section{Plate 2}

Fig. 7. Intercalary spore formation in slide culture. Nutrient agar. M. faeni A94 $(\times 800)$.

Fig. 8. Intercalary spore formation in slide culture. Nutrient agar M. faeni A94 ( $\times$ I 600$)$.

Fig. 9. Slide culture, dried and Gram stained. M. faeni A94 $(\times 2000)$.

Fig. 10. Slide culture, dried and Gram stained M. faeni CUB $58(\times 2000)$.

Fig. I I. Electron micrograph of aerial mycelium spores $M$. faeni A $445(\times 7200)$.

Fig. 12. Electron micrograph of aerial mycelium spores. M. faeni A $94(\times 28,800)$. 